\title{
From the history of the use of vaginal pessary in obstetric and gynaecological practice
}

\author{
Vladimir K. Chelpanov ${ }^{1}$ \\ 1 FSBEI HE “A.I. Yevdokimov Moscow State University of Medicine and Dentistry” \\ 20 Delegatskaya St., building 1, Moscow 127473, Russia
}

Corresponding author: Vladimir K. Chelpanov (chevl@inbox.ru)

Received: 28 December 2018 Accepted: 06 May 2019 Published online: 15 July 2019

Citation: Chelpanov VK (2019) From the history of the use of vaginal pessary in obstetric and gynaecological practice. History of Medicine 6(2): 88-92. https://10.17720/2409-5834.v6.2.2019.04d

\begin{abstract}
In this article, the main stages of the evolution of the medical pessary and its role in obstetric and gynaecological practice are studied. The author pays considerable attention to the description and comparison of the forms, quality and purpose of pessaries in different periods, as well as the materials used for their manufacture.

The history of the use of pessaries dates back thousands of years and contains references to many forms and sources of their manufacturing, from Hippocrates and Soranus of Ephesus to the present day. Pessaries have always had special importance in obstetric and gynaecological practice since they have long been a universal means of helping women to maintain the uterus in uterine prolapse and prevent unwanted pregnancy.

The conducted historiographic study allowed us to divide the evolution of the medical pessary into three stages: from ancient time to the 18th century, from the beginning of the 19th century to the first half of the 20th century, and from the second half of the 20th century to the present day. Obstetric pessaries have come a long way in terms of development - from sponge pessaries, oval stones, wooden and rubber plugs to highly elastic silicone rings, and over the entire period of their existence there have been more than 200 types that differed in purpose, form and mechanism of action, as well as the qualitative characteristics of materials used for their manufacturing. In the modern line of pessaries, the most popular are the pessaries of Dr. Arabin and the Juno brand. It is indicated that nowadays the pessary in obstetric and gynaecological practice is an indispensable and alternative solution for the treatment of uterine and vaginal prolapse, pelvic organ prolapse, urinary incontinence in women, and the prevention of preterm labour.
\end{abstract}

\section{Keywords}

history of medicine, obstetric pessary, Hodge pessary, isthmic-cervical insufficiency, prolapse of pelvic organs, uterine circle, prevention of preterm birth

Nowadays, obstetric and gynaecological practice widely uses pessaries of various forms and designs determined by their purpose. A pessary is a silicone or plastic device that is inserted into the vagina to support the pelvic organs (uterus, bladder, rectum) ${ }^{1}$ It belongs to the class of medical supplies used in obstetric and gynaecological practice for prevention and treatment

\footnotetext{
The term pessary comes from the Latin word pessarium which literally translates as "vaginal". In ancient Greek, this word also meant "ring". There is also another opinion that the name "pessary" is derived from the Greek word pessos meaning "round stone game-piece".
}

of urinary incontinence, pelvic organ prolapse, pelvic floor dysfunction, as well as shortening of the cervix in pregnant women with comorbid cervical insufficiency (Egorova and Rybalka 2014).

The analysis of scientific literature and historiographic sources allows us to conventionally divide the evolution of the medical pessary into three stages: 1) from ancient times to the 18th century; 2) from the beginning of the 19 th century to the first half of the 20th century; 3 ) from the second half of the 20th century to the present day.

The division into these stages is due to the characteristics of the types, forms, composition and purpose of pessaries used in medicine. 
The first mentions of uterine prolapse and the cup or ring-shaped devices used to eliminate discomfort in the vagina are found in the ancient Egyptian papyrus dating back to $2000 \mathrm{BC}$. The ancient prototypes of the pessary served as an integral part of the arsenal of treatment of pelvic organ prolapse in women for more than a thousand years. Those were pomegranates soaked in tartaric acid, or other fruits suitable for intravaginal use in size, shape and quality. The acid contributed to the "mummification" of fruits, making them thick and resistant to the effects of biological environments.

The famous ancient Greek healer, physician, philosopher and 'the father of medicine' Hippocrates (460-370 BC) used round objects and adapted rings to fix the prolapsed uterus and cervical insufficiency. Vaginal devices were made of bronze, cotton, wool and flax. T-shaped garters were used to hold the pessaries in place.

In his Diseases of Women essay, Hippocrates wrote about cervical insufficiency and uterine prolapse. The physician believed that one of the goals of therapy was to give a sterile woman the ability to bear children, for which the uterus should be treated as an organ of reproduction: "Fertilisation may be absent due to various reasons, for example, if the male seed does not reach the uterus, or, having got inside, does not stay there. Fertilisation cannot take place if the cervix is not in a normal position, if it is slanted or bent in one direction or another, or if the cervix is closed and impassable due to induration. The seed is also not retained by the uterus if the opening of the cervix is gaping" (Menie 1926, p. 122). For the treatment of cervical insufficiency during pregnancy, Hippocrates used pessaries which were pieces of fabric soaked with medicinal substances in combination with resin, wax, goose fat, deer bone marrow and honey, and also tied a thread to the pessary so that it was possible to easily remove the device from the vagina. Hippocrates believed that this method would prevent miscarriages in pregnant women, and also help women suffering from uterine or vaginal prolapse. For the treatment of inflammatory processes in the vagina and cervix, Hippocrates used pessaries with aromatic substances (garlic, seal fat, dill, Ethiopian cumin, etc) implemented by inserting a reed connected to a large receiver (a device which dispensed the aforementioned substances) into the uterus (Menie 1926).

The findings of historians at the excavations in Pompeii suggest that the ancient Roman encyclopaedic scholar Aulus Cornelius Celsus (25 BC-50 AD), who was involved not only in philosophy, rhetoric, agriculture and military affairs, but also in medicine, applied pessaries in the form of bronze rings.

The oldest extant medical text dedicated to the treatment of genital prolapse belongs to Soranus of Ephesus (98-138), an ancient Greek physician who worked in Rome. Soranus made a fundamental contribution to the development of obstetrics and gynae- cology in Rome during the reign of emperors Trajan and Hadrian. In his book On Midwifery and the Diseases of Women, which remained the main source of information on obstetrics, gynaecology and paediatrics until the 17th century, he described methods for treating uterine prolapse, such as hanging a woman upside down for one day and using aromatic substances orally. At that time, physicians believed that the uterus, like an animal, would go back inside having "smelled" a pleasant scent. Another method involved tying a dead rodent or lizard to the prolapsed uterus in the hope to "frighten" it and make it return to the correct position. These and other charlatan methods were sharply criticised by Soranus. In turn, he proposed tamponing of the vagina with wool tampons soaked in olive oil. After the uterus was repositioned with such a tampon, the woman's legs were tied together and she would have to lie down for three days. Later they began to use natural analogues of pessaries - pomegranate fruits, which were inserted into the vagina either entirely or partially, using only their hollow halves (resembling a cup), which is mentioned in the work of Soranus of Ephesus On Midwifery and the Diseases of Women.

Moschus (117 AD) believed that a woman would be capable of childbearing with his invention - a special pessary - and left a guide for midwives, giving a complete picture of the "small obstetrics" of the first century of our era. In this guide, Moschus highlighted the issues of anatomy and pathology that would become necessary in midwifery. He recommended that during the 7th month of pregnancy, when the foetus grows significantly and becomes heavier, women should be prescribed pessaries - pieces of fabric soaked with myrtle or vegetable oil, and during the 9th, in order to facilitate the delivery, he recommended pessaries made with goose fat or deer bone marrow (Menie 1926).

In the 7th century, Paul of Aegina (608-690), a famous Greek surgeon and obstetrician, practiced in $\mathrm{Al}-$ exandria. He became the first male obstetrician who suggested using a wool tampon soaked with medicines as a pessary. It was inserted into the cervix, which, according to the physician, contributed to the resetting of the uterus.

During the 9th-12th centuries, Trota of Salerno - a female doctor who worked in Salerno (Italy) - made ball-shaped pessaries from strips of bed linen. She is credited with several works on women's health, including women's diseases, treatment and cosmetics.

In the 15th century obstetricians used a tightly folded sponge soaked with wax and oil and installed in the vagina as a pessary.

In the 16th century, Ambroise Paré (1510-1590), a French surgeon and obstetrician, the reformer of surgery who was considered one of the fathers of modern medicine, also worked with female diseases. He wrote works on obstetrics, in particular he restored the "podalic version" which had been forgotten for many cen- 
turies, as well as the caesarean section following the death of a woman in labour (forgotten after Soranus of Ephesus's time). He first proposed to use ring-shaped pessaries instead of the usual oval stones to support the pelvic organs. Paré made oval-shaped vaginal pessaries from brass or waxed and polished wood (Diterikhs 1926).

Jacques Primrose (1592-1659) studied medicine in Paris and Montpellier, later settling in Hull, Yorkshire. Primrose considered himself the author of the most complete work on women's diseases, in which, like his predecessors, he described the treatment of such diseases as vaginal prolapse, cervical insufficiency and inflammatory diseases of the cervix and vagina with a medicine-infused pessary.

In 1701, the Dutch surgeon Hendrik van Deventer published The Art of Midwifery Improv'd (Hendrix et al. 2002), in which he gave a detailed description of the pessaries of that time. He mentioned four kinds of ring-shaped vaginal devices, which were flatter ("dishshaped") and came in three shapes (triangle, oval or circle) with a hole in the middle. Natural materials (wood, cork, silver and gold) were used for their manufacture. The devices made from cork and wood were waxed before insertion into the vagina in order to avoid irritation of the mucous membrane and the development of purulent inflammatory processes. The first detailed instructions on the technique of pessary insertion and their correct positioning relative to the cervix belong to none other than Hendrik van Deventer.

19 th century's pessaries are, as a general rule, ingeniously shaped devices made of bone, bronze, copper and other metals which surpass their predecessors in terms of reliability and functionality. Their study causes mixed feelings - from respect for the ingenuity of the physicians of that time, to horror - some pessaries look more like torture implements, rather than medical devices.

In 1839 , the discovery by the American inventor Charles Nelson Goodyear (1800-1860) of the process of vulcanisation of rubber, affected the further development and production of medical pessaries. It was a breakthrough. The material was remarkably resilient, elastic and stable in biological environments, which made it possible to reduce the number of purulent complications when using pessaries and prolong their service life, and by the mid-19th century, the first rubber vaginal rings (uterine rings), which had a longer period of use, began to appear.

In 1860, Hugh Lenox Hodge, a professor of gynaecology at the University of Pennsylvania, developed a device made of vulcanised rubber, known even today as the Hodge pessary, which, due to its oblong shape, more closely fitted the anatomical shape of the vagina and was more suitable for reducing pressure on the rectum and setting the body of the uterus in the correct position.
In 1900, a pessary plaited from twigs of young birch trees was popular. It looked like a coiled thread, or a rubber ball. This type of device was used in uterine and vaginal prolapse (Yampolskiy 1900).

Rubber was the main raw material for the manufacturing of pessaries until 1950, when the first plastic pessary was made.

Starting from 1950, the previously used rubber pessaries were replaced by plastic ones, and later devices made of soft hypoallergenic silicone that met the requirements of modern medicine and were most comfortable for patients, were introduced.

V.F. Grobel wrote about the KR pessary, which was used not only to correct vaginal prolapse and cervical insufficiency in pregnant women, but also to protect against unwanted pregnancy. But this type of pessary couldn't always be recommended in 2nd- and 3rd-degree perineal tears during labour or in flattening of the anterior vaginal wall, etc. So V.F. Grobel suggested creating a new, more convenient and effective type of pessary. This was facilitated by the rapid development of the chemistry of high molecular compounds and the creation of new, high-quality vaginal pessaries made from elastomers that could be used in medical practice. In terms of elasticity, the pessary had to exceed all existing mechanical contraceptives and be applicable in many anatomical deviations in the female genitalia. This pessary was kept on the vaginal vaults not by high negative pressure, i.e. suction force, but mainly by close contact with the mucous membranes of the vagina and cervix. The vault pessary had a significant capacity of $15-25 \mathrm{ml}$, due to which it did not cause blockage of the cervical canal, and its elasticity eliminated the possibility of cervical oedema and congestion in the upper genital tract. For manufacturing of such pessaries V.F. Grobel suggested three types of moulds - for stamping, pressing followed by polymerisation and injection moulding. These moulds were made from U8A carbon tool steel and structural carbon steel St.20. Special electric furnaces with a thermostatic device were used for the polymerisation of plastics and the vulcanisation of rubbers, and an injection syringe machine in which fluid polymers were melted was designed for injection moulding (Grobel et al. 1962).

The first elastomer use by him was EGmass- 12 (Elastic Hygienic plastMass), created in the experimental laboratory of plastics of the Central Institute of Traumatology and Orthopaedics. Pessaries made from this type of plastic have good elasticity, which can be varied by changing the proportions of PVC and plasticiser dibutyl phthalate in the powder mixture. EGmass-12 pessaries are not destroyed by the vaginal secretion and retain their shape and smooth surface for a long time. Their shelf life in continuous use is 6 months. The second elastomer used to manufacture the pessaries was a polyethylene blend containing $70 \%$ polyisobutylene POV-70. Pessaries made from this plastic have good 
elasticity and do not change because of the effects of the vaginal secretion; their shelf life can be as high as 1-1.5 years. An unpleasant brownish-grey colour is one of the disadvantages of polyethylene combined with polyisobutylene. The third elastomer was natural rubber (light crepe). With the help of various rubber compounds, it was possible to make highly elastic vault pessaries that kept their shape well. In terms of physical qualities, pessaries made of light crepe are significantly superior to the products made from plastics - EGmass-12 and POV-70; their shelf life ranges from 1 to 1.5 years. They tolerate boiling well and do not change under the influence of the vaginal environment for a long time. V.F. Grobel also studied the effect of this type of pessary on the vaginal flora and found that the vaginal device, if used for a short period of time, does not affect the vaginal microflora in any way (Grobel et al. 1962).

In the 1950s, the German obstetrician and gynaecologist Hans Arabin developed various types of pessaries made of silicone. In 1959, Irish physicians published for the first time the results of using a gynaecological pessary in 13 patients $^{2}$ (Arabin and Alfirevic 2013). In the US, the Hodge pessary was successfully used to treat cervical insufficiency in patients with Ehlers-Danlos syndrome (a hereditary systemic disease of the connective tissue caused by a defect in collagen synthesis) (Bespalova and Sargsyan 2015).

Birgit Arabin, a well-known neonatologist who received worldwide recognition and in the 1970-1980s, turned this invention into a medical innovation (Rylov 2013) and continued the business of her father, the German inventor Dr. Arabin.

In 1991, Medical Enterprise Simurg Ltd. patented and issued an unloading obstetric pessary in the shape of a butterfly, by the Juno brand. Plastic was also used as a material for the manufacturing of the pessary, which was due to the performance qualities of the material - first of all, its sufficient rigidity, allowing to maintain the shape and withstand the pressure of the heavy uterus. In this case, the selected plastic was distinguished by absolute inertness to the vaginal environment, which guaranteed the safety of the product for the mother and foetus.

In 1999, Belarussian specialists, together with scientists and physicians, developed a plastic uterine pessary in the shape of a perforated cup. This pessary became a timely support for many pregnant women, as well as women suffering from various forms of genital prolapse.

In 2014, Simurg began producing silicone pessaries for solving gynaecological, urological and obstetric problems. Silicone - an elastic, resilient and at the same time soft and atraumatic material - was used in the manufacturing of new pessaries for the first time.

Before treatment, there were 7 cases of urgent delivery out of 54 pregnancies in those patients' anamneses in total. After the pessary fitting, 11 out of these 13 women gave birth to viable babies.
Medical silicone by the German company Wacker Chemie AG, chosen for the manufacturing of pessaries, demonstrated absolute compliance with the developer's requirements and did not display any toxic and teratogenic effects, which was important for ensuring the safety of the product.

So, the evolution of pessaries gradually led to a significant improvement in their functionality and significant diversity in the medical devices market.

All existing pessaries can be divided into two large groups - supporting and volumetric pessaries, with the latter, in turn, being divided into pessaries with and without a hole.

Supporting pessaries include vaginal rings and lever pessaries.

Vaginal rings are the most popular of all pessaries. They are effective in 1st- and 2nd-degree uterine and vaginal prolapse, cervical insufficiency, prolapse of the bladder and rectum and enterocele, and can also be used in urinary incontinence. The advantage of the ring pessary is that it is easy to fit both by the doctor and the patient, so vaginal rings, in essence, do not limit sexual activity.

Lever pessaries (Hodge pessary, Smith and Risser pessaries) are rarely used, their fitting requires a certain skill, such pessaries must be installed by a doctor, because first the uterus is manually reset, and then fixed by the pessary in the selected position. Gehrung and Shaatz pessaries are suitable for the treatment of bladder and rectal prolapse.

Volumetric pessaries keep both the uterus and neighbouring organs from sagging. They are suitable for the treatment of 3rd- and 4th-degree prolapse. These pessaries can be fitted into wide vaginas as well, including after removal of the uterus - the pessary stem does not allow it to move downwards. The volumetric pessary is fitted by a doctor. Sexual activity is impossible with such a pessary (Shneyderman and Apolikhina 2013).

Modern types of pessaries are represented by the following kinds: 1) silicone "ring" and "thick ring" pessary; 2) silicone "cup" and "perforated cup" pessary; 3) urethral silicone pessary; 4) cup-urethral silicone pessary; 5) Hodge silicone pessary; 6) perforated silicone cervical pessary; 7) cubic silicone pessary; 8) mushroom-shaped silicone pessary.

The use of obstetric pessaries not only reduces the incidence of preterm labour, but also has significant economic and social benefits, allowing pregnant women to avoid unnecessary hospital admissions and continue their professional activities (Medvedev 2015).

Pessaries have been used in Russia for quite a long time, but only recently Dr. Arabin's pessaries have appeared in the domestic market. Worldwide, pessaries made by different manufacturers are now used, but the pessaries designed by Dr. Arabin have received the greatest recognition in the last 10 years due to their high efficiency and comfort in use, as well as the simplicity of fitting. 


\section{References}

Arabin B, Alfirevic Z (2013) Cervical pessaries for prevention of spontaneous preterm birth: past, present and future. Ultrasound in Obstetrics and Gynecology 42 (4): 390-399.

Bespalova ON, Sargsyan GS (2015) Akusherskie pessarii v klinicheskoy praktike [Obstetric pessaries in clinical practice]. Saint Petersburg: FGBNU “NII AGiR im. D.O. Otta”. P. 97-107. (In Russ.)

Diterikhs MM (1926) Ambruaz Pare [Ambroise Paré]. Novyy khirurgicheskiy arkhiv [New surgical archive] 11(43): 247. (In Russ.)

Egorova YaA, Rybalka AN (2014) Razgruzhayushchiy akusherskiy pessariy kak dopolnenie $\mathrm{k}$ lecheniyu istmiko-tservikalnoy nedostatochnosti [Relieving obstetric pessary as an adjunct to the treatment of cervical weakness]. Krymskiy zhurnal eksperimentalnoy i klinicheskoy meditsiny [Crimean Journal of Experimental and Clinical Medicine] 4(2): 17-21. (In Russ.)

Grobel VF, Grobel OV, Bojchevskaya MV (1962) Pessarij iz elastomerov, kak mekhanicheskoe protivozachatochnoe sredstvo [Elastomer pessary as a mechanical contraceptive]. Akusherstvo i ginekologiya [Obstetrics and gynecology] 5: 112-114. (In Russ.)

Hendrix SL, Clark A, Nygaard I, Aragaki A, Barnabei V, McTiernan A (2002) Pelvic organ prolapse in the Women's Health Initiative: grav- ity and gravidity. American Journal of Obstetrics and Gynecology 186(6): 1160-1166.

Medvedev MV (2015) Primenenie pessariev v ginekologicheskoy praktike s tselyu lecheniya opushcheniya polovykh organov i stressovogo nederzhaniya mocha [Use of pessaries in gynecological practice for the purpose of treating genital prolapse and stress urinary incontinence]. Electronic resource. Access mode: http://www.medvedev.ua/ knowledge-base/articles/. (In Russ.)

Menie L (1926) Istoriya meditsiny: s prilozheniem ocherka istorii [History of medicine: with an attachment of a history essay]. Moscow: Leningrad. 322 p. (In Russ.)

Rylov A (2013) Pessarii doktora Arabin [Pessaries of Dr. Arabin]. Meditsinskiy vestnik [Medical Bulletin] 15: 1-3. (In Russ.)

Shneyderman MG, Apolikhina IA (2013) Pessarii - novye modeli i novye vozmozhnosti [Pessaries - new models and new opportunities]. Meditsinskiy sovet [Medical Council] 6: 102-105. (In Russ.)

Yampolskiy SD (1900) Samodelnyy derevenskiy pessariy [Homemade rustic pessary]. Saint Petersburg: Sankt-Peterburgskaya gubernskaya tipografiya. 3 p. (In Russ.)

\section{About the author}

Vladimir Konstantinovich Chelpanov - Obstetrician-gynecologist, postgraduate student, KGBUZ Maternity hospital № 3 of the Health Ministry of Khabarovsk region, gynecological department; FSBEI HE "A.I. Yevdokimov Moscow State University of Medicine and Dentistry”, Dental faculty, Department of Obstetrics and Gynecology, Moscow. Email: chevl@ inbox.ru 